\title{
Design of Enterprise Training Model Based on Dynamic Knowledge Creation
}

\author{
Minjing Xu \\ College of Management, Jinan University, Guangzhou, China \\ Email: tsuimandhing@163.com
}

How to cite this paper: Xu, M.J. (2019) Design of Enterprise Training Model Based on Dynamic Knowledge Creation. American Journal of Industrial and Business Management, 9, 1761-1771.

https://doi.org/10.4236/ajibm.2019.99115

Received: August 3, 2019

Accepted: August 30, 2019

Published: September 2, 2019

Copyright $\odot 2019$ by author(s) and Scientific Research Publishing Inc. This work is licensed under the Creative Commons Attribution International License (CC BY 4.0).

http://creativecommons.org/licenses/by/4.0/

\begin{abstract}
With the development of the knowledge economy society, the key of the enterprise success lies in the cultivation and exploration of talents. The traditional enterprise employee development training model fails to meet the efficient knowledge sharing and transformation. This paper combines dynamic knowledge creation theory to study the enterprise training system. Enterprise dynamic knowledge creation is the most widely used knowledge management research theory. By combing the theoretical relationship between dynamic knowledge creation and enterprise training process, this paper combines the four kinds of knowledge transformation methods (Socialization, Externalization, Combination, and Internalization) to construct the enterprise employee training model, and obtain the "learning-doing-teaching" dynamic knowledge creation cycle training system.
\end{abstract}

\section{Keywords}

Dynamic Knowledge, Knowledge Creation, Training, Knowledge Management

\section{Introduction}

In the current market environment, companies can develop sustainably only if they are competitive. Enterprise innovation capability is the key for companies to gain competitiveness in the market. Knowledge Bridge Consulting's research found that knowledge management can promote innovation, fill the market gaps, and help companies gain market competitiveness. Knowledge management is based on the knowledge mining and knowledge sharing system of business content and functions of enterprises, and enhances the resilience and innovation ability of enterprises to maintain and enhance the core competitiveness of en- 
terprises [1]. Knowledge transfer mechanism of knowledge management is conducive to transforming internal knowledge into external knowledge, transforming tacit knowledge into explicit knowledge, which promotes enterprises to acquire, reserve and share knowledge.

An effective training system is one of the important ways for enterprises to gain core competitiveness. Enterprise training aims to optimize employee values, innovate the work ideas of employees, tap and maximize the potential of employees, and achieve the simultaneous development of employees and enterprises. Most enterprises now have problems such as lack of scientific enterprise training system and low efficiency of employee training. How to design, implement and evaluate corporate training has become a major problem for enterprise managers. Madhavan et al. (1998) and Popadiuk et al. (2006) argue that corporate development is the result of the transformation and absorption of dynamic knowledge [2] [3]. With the help of the dynamic knowledge creation process, companies can create, transform, and leverage knowledge. This paper sorts out the theoretical relationship between dynamic knowledge creation process and enterprise training, to establish an enterprise training model based on the dynamic knowledge creation process, including Socialization, Externalization, Combination, Internalization, the four knowledge transformations. Finally, this paper obtains "learning-doing-teaching" two-way cycle enterprise training model.

This paper designs the enterprise training development and innovation model on the basis of dynamic knowledge creation. On the one hand, it provides innovative ideas and ideas for enterprise training, and provides a new perspective for the positioning, process and strategy of enterprise design training system. On the other hand, with the use of the SECI model, this paper explores the enterprise staff training development model and the dynamic knowledge creation theory, which provides an innovative way for enterprises to transform human capital.

The research structure of this paper is as follows. Section 1 will introduce the background and significance of the research. Section 2 will introduce the theory of enterprise training and dynamic knowledge creation process. Section 3 will introduce the relationship between dynamic knowledge creation and enterprise training, which contains the knowledge transformation and knowledge spiral process of enterprise training. Section 4 will propose a four-knowledge transformation model of "learning-doing-teaching" based on dynamic knowledge creation theory. Finally, Section 5 will summarize the results of this paper and proposes future research efforts.

\section{Enterprise Training and Dynamic Knowledge Creation Theory}

\subsection{Enterprise Training}

\subsubsection{Definition of Enterprise Training}

Enterprise training refers to the process of teaching employees the basic skills necessary to complete his or her job [4]. In the traditional concept, enterprise training is generally targeted to a specific task, in line with the actual work and 
tasks need to be carried out. However, with the development of modern society, the concept and scope of corporate training has been expanding. Human resource training and development generally refers to the improvement of employees' ability through the learning of employees, or changes the attitude of employees, or increase their knowledge and skills, in order to change the current or future performance of employees [4].

\subsubsection{Purpose of Enterprise Training}

Enterprise training is to improve the management and technical level of the enterprise, improve the work ability and quality of the employees and exert their potential, so that the various tasks of the enterprise can be carried out smoothly. Enterprises will have different development needs at different stages of development. On the one hand, enterprise training can improve the professional level of employees to meet the business needs of enterprises. On the other hand, it is to cultivate talents for enterprises to adapt to the development of business.

\subsubsection{Principles of Enterprise Training}

Enterprise training is extensively classified and the requirements for each training are inconsistent. When training enterprises to train employees, they should grasp the following training principles [5]. First, training should meet the actual needs of enterprises. Secondly, enterprise training should handle the relationship between the organization's recent development goals and long-term strategy. Third, need to pay attention to the principle of learning. Fourth, pay attention to the principle of individual differences. Fifth, strengthen the feedback of training effects.

\subsubsection{Traditional Training Problem}

Enterprises generally use traditional training theories to guide training, including training needs analysis, training plan development, training activities organization and implementation and training effectiveness evaluation [5]. The traditional enterprise training model has problems, such as unclear training needs, imperfect training evaluation mechanism and lack of training platform transformation results of employees, which will lead to unsatisfactory training results and low training efficiency [5].

\subsection{Enterprise Dynamic Knowledge Concepts}

\subsubsection{Explicit Knowledge and Tacit Knowledge}

With the use of knowledge in practice, knowledge classification is becoming more diverse. Michael Polanyi (1958) first divided human knowledge into explicit knowledge and tacit knowledge [6].

Explicit knowledge is knowledge expressed in the form of words, numbers, sounds and so on. It is shared in the form of data, scientific formulas, visual graphics, sound tapes or product manuals. Explicit knowledge is encoded and formatted, and users have a clear understanding of explicit knowledge. Tacit knowledge belongs to the invisible knowledge, which is difficult to express. It is 
highly personalized and difficult to be specific, such as certain expertise, embarrassment, experience and so on. Tacit knowledge consists of two levels. The first level is the technical level, including informal and difficult to define skills and crafts, often referred to as "Know-how", derived from hands-on experience. The second level is the "cognitive" level, including beliefs, comprehension, ideals, values, and mental models. These cognitive factors are deeply rooted in our thinking and difficult to change.

\subsubsection{Knowledge Assets of the Knowledge Creation Process}

Knowledge is widely recognized as one of the most important assets for companies to create sustainable competitive advantage. Knowledge assets are the input, output and adjustment factors of the knowledge creation process [7]. Most companies lack effective systems and tools to assess and manage knowledge assets, making them unable to realize the true value of knowledge assets. To understand how knowledge assets are created, acquired, and developed, Nonaka (2000) divides knowledge assets into four types: experiential knowledge assets, conceptual knowledge assets, systemic knowledge assets, and routine knowledge assets [7]. Experiential knowledge assets are tacit knowledge by sharing common experience, which includes individual skills, secrets, emotions, etc. Conceptual knowledge assets refer to images, symbols, and languages, including product concept, design, brand, etc. Routine knowledge assets refer to the tacit knowledge embedded in the behavior and practice, including the "know-how" of daily operations, organizational culture, organizational habits, etc. Systemic knowledge assets refer to systemized, standardized explicit knowledge, including documents, specifications, manuals, databases, patents and licenses.

\subsection{SECI Model and Knowledge Spiral Process}

\subsubsection{Knowledge Transformation Creation}

The SECI model is called the knowledge creation spiral model. Yujiro Nojiro and Takeuchi Takeuchi proposed that organizations can create and utilize knowledge through the conversion between tacit knowledge and explicit knowledge [8]. The knowledge transformation process of the SECI model consists of four phases, including socialization, externalization, combination, and internalization.

Socialization refers to the process of transforming from tacit knowledge to tacit knowledge, by sharing personal experience [9]. Lave et al. (1991) stated that personal expertise is transferable, and that team members can communicate and understand skills and values that are difficult to express by interacting with others and participating in group activities [10]. Personal interaction can provide immediate feedback and is one of the rich and effective forms of communication [11]. Externalization refers to the process from tacit knowledge to explicit knowledge, which can be realized by describing, debating or self-reflecting the work process, and the process of creating, sharing, distributing and exchanging information can be externalized [9]. The creation, sharing, distribution and exchange of information can be externalized, that facilitates the observation and participa- 
tion of others [12]. Combination is a process from explicit knowledge to explicit knowledge, that is, through the integration of explicit knowledge from various sources to fulfill the knowledge base. Nonaka and Konno (1998) argue that combination is the process of transforming localized knowledge into resources available to the organization [9]. In this process, another form of knowledge base is provided, which can be used as a resource for the organization's knowledge management cycle [13]. Internalization refers to the process from explicit knowledge to tacit knowledge, and the process of transforming explicit knowledge into personal tacit knowledge [9]. Internalization is also a process of evaluating and integrating knowledge into daily work procedures [14].

\subsubsection{Knowledge Dynamic Spiral Process}

Knowledge creation is a dynamic process in which tacit knowledge and explicit knowledge continue to interact [9]. The individual tacit knowledge is magnified by the four modes of knowledge transformation at the organizational level and fixed in the team and organization. This process is called the knowledge spiral process. In the process of knowledge spiral, the socialization model begins with creating a ba of interaction, realizing socialization through direct experience sharing and creating tacit knowledge. Secondly, using dialogue or reflection, applying appropriate metaphor or analogy to tacit knowledge for the implement of externalization. Then, the explicit knowledge and information are systematically and utilized to implement the combination. Finally, new tacit knowledge is learned and realized to achieve internalization in practice.

\subsection{Summary}

By combing the theory of enterprise training, the process of training is mainly carried out with the idea of discovering problems-diagnosing problems-solving problems. This traditional training model is based on the discovery of problems in knowledge and skills, but it does not include attitude questions. If the training needs cannot be discovered, then the traditional training model does not make any sense.

The ultimate goal of training is not to improve the efficiency of employees, but to improve the business development capabilities of enterprises. In short, it is necessary to enhance the ability of enterprises to create knowledge independently. Based on the four knowledge transformation of dynamic knowledge creation process to re-build the enterprise training workflow, it can not only promote the mutual transformation of knowledge among employees and create new knowledge for enterprises, but also solve the problems of traditional training models, and form a cycle of enterprise training processes, which find a solution to make up for the lack of traditional training models.

\section{The Relationship between Dynamic Knowledge Creation and Enterprise Training}

\subsection{The Knowledge Transformation of Training}

Dynamic knowledge creation includes socialization, externalization, combina- 
tion and internalization, which indicates that enterprises continue to create knowledge through the continuous conversion of tacit knowledge and explicit knowledge, and obtain core competitiveness for enterprises.

\subsubsection{Socialization Process of Enterprise Training}

Socialization refers to the transfer of one's tacit knowledge to the other's tacit knowledge [13]. This process often occurs when people interact and influence each other. The most classic example of socialization is the master system in traditional industry. In enterprise training, you can use the method of socialization to transfer knowledge, but the two conditions must be met (Figure 1). First, whether the knowledge to be passed is tacit knowledge. Secondly, create an environment where employees can communicate face to face. After achieving these two preconditions, it is necessary to develop a series of related systems to organize the employees of the company into the socialization and promote the transfer of knowledge in the training process.

\subsubsection{Externalization Process of Enterprise Training}

Externalization refers to the process of transforming tacit knowledge into explicit knowledge [13]. Within the enterprise, the process of externalization knowledge transformation is often defined as experience summary process and the practice to theory process. The externalization process is an important part of enterprise training. After the personal work experience and learning knowledge are externalization, the knowledge storage is carried out in the form of enterprise knowledge base and case library, and the knowledge reserve and utilization rate of enterprise training are increased.

\subsubsection{Combination Process of Enterprise Training}

Combination refers to the process of explicit knowledge to explicit knowledge [13]. Training courses, theme seminars and other training methods are the process of combination. The training instructor logically edits some of the theoretical knowledge, prepares to become a training course tutorial, and then teaches in the class. With the development of network technology, the way of enterprise training is becoming more and more electronic. For example, E-learning is one of the important ways to realize training.

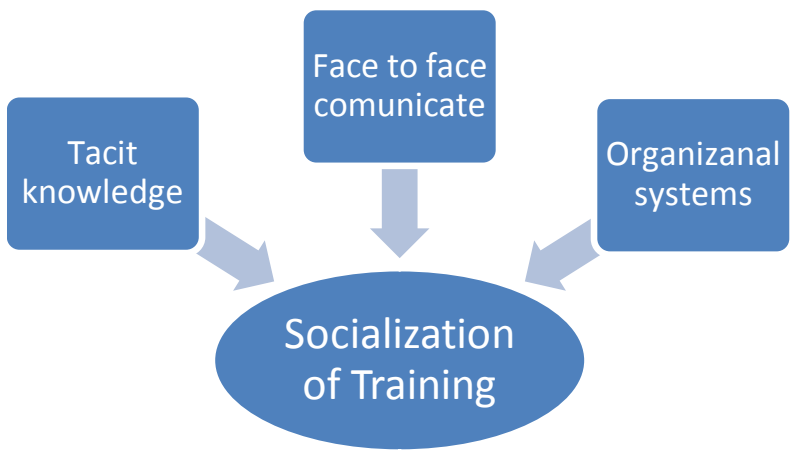

Figure 1. The factors of training socialization process. 


\subsubsection{Internalization Process of Enterprise Training}

Internalization refers to the conversion of explicit knowledge into personal tacit knowledge [13], which is the ultimate goal of corporate training. Only explicit knowledge becomes the tacit knowledge of individuals through internalization, which is transformed into the internal knowledge assets and core competitiveness of enterprises. After the training course is over, the company should not pay attention to whether the employees understand and master certain job skills, but whether the employees can apply the training knowledge to the actual work after the training. Therefore, the end of the training is only the completion of the explicit knowledge combination process, and has not yet reached the internalization process. After the training, the post coaching and training feedback are further work of internalization.

\subsection{Knowledge Spiral Process of Enterprise Training}

Peter Senge proposes that, learning organizations include systematic thinking, self-transcendence, improvement of mental models, establishment of shared vision, and group learning [15]. System thinking practice encourages employees to see the whole from the perspective of the fragment. Self-transcendence is the study and cultivation of personal growth, but only through individual learning can the organization learn. Group learning encourages employees to share knowledge in groups as a unit to achieve consensus action. In a learning organization, enterprises transform their personal knowledge into organizations through training, and then internalize organizational knowledge to individual employees. This cyclical knowledge process is the process of knowledge spiral transformation. Enterprise training encourages employees to learn new knowledge and new skills from the individual, realize knowledge socialization through mutual communication, and then use information system technology to realize knowledge externalization, realize knowledge combination with traditional and emerging training methods, and finally internalize employee personal knowledge into organizational knowledge and form a process of knowledge spiraling [16].

\section{Design of Enterprise Training Model Based on Dynamic Knowledge Creation}

In the process of dynamic knowledge creation, the knowledge transformation method refers to the spiral process of continuous development [17]. Therefore, the processes of socialization, externalization, combination and internalization for enterprise training are important processes for enterprise training. Combined with the training theory and status, this paper finds that enterprise training is to pass the work skills and knowledge to the employees according to the work needs of the enterprise, and achieve the goal that employees can apply the training knowledge in practical work. This process is the dynamic knowledge creation of explicit knowledge into tacit knowledge. According to the analysis of the relationship between dynamic knowledge creation and enterprise training, this paper proposes a four-knowledge transformation model of "learning-doing-teaching" based 
on dynamic knowledge creation theory.

\subsection{Learning: Setting Up the Course According to the Training Content}

Learning is the process of training and learning in the traditional sense. However, learning covers a wide range, and it can be experiential training of words and deeds, as well as traditional theoretical classroom training. The knowledge of learning is different, and the methods of knowledge conversion are different, including socialization, externalization and combination [18].

We divide the enterprise training courses into institutional and regulation knowledge, personal development knowledge, and business knowledge. Institutional and regulatory knowledge is mainly recorded in written form on paper materials such as company operation rules and employee handbooks [18]. This kind of knowledge is the basis for the organization to carry out normal work, and the integrity of knowledge is not lost due to the departure of individual employees [19]. Because of the high transferability and coding characteristics of this type of knowledge, it is easy to store and accumulate in the enterprise. Enterprises can use the E-Learning information technology from explicit knowledge to explicit knowledge, to upload the enterprise rules and regulations to the enterprise network platform [20].

Personal development knowledge is mainly tacit knowledge such as work skills, knowledge quality and experience accumulated by employees in their positions [18]. This type of knowledge is difficult to express because of its high implicitness. Mastering this kind of knowledge is the key to the new employee's ability to work independently as soon as possible, so companies can be transformed from tacit knowledge into socialized tacit knowledge. The mentoring system is the usual practice of knowledge socialization. The new employees are led directly by the old employees. The old employees are subtly guiding and coaching in the work, and the new employees observe and master the work steps.

Business knowledge belongs to comprehensive explicit knowledge, from relevant theoretical knowledge, employee work experience [18]. Enterprise training can be done using the combination and dynamic knowledge, that employees must not only understand this knowledge and skills, but also know how to use this knowledge in their work. Therefore, the training focus of this kind of knowledge is internalization, that the training course must include role and on-the-job operation [20].

\subsection{Doing: The Internalization Process of Training Knowledge}

Doing is the process in which employees apply the knowledge and skills they have learned in training and practice to their positions. The internalization process from explicit knowledge to tacit knowledge in the SECI model is the ultimate goal of enterprise training [9].

The focus of doing is that the employees apply the knowledge learned by the 
training to the position job that realizes the knowledge internalization process. The scoring questionnaire is a general traditional training assessment method, but this method does not objectively and comprehensively explain the effectiveness of the training [21]. Therefore, the enterprise training assessment can also conduct the practical work with the form of an open questionnaire.

The focus of the training is not on the training assessment, but on the training tracking. Tracking feedback is used in the actual work, which is also the internalization process of dynamic knowledge creation. On-the-job training can be called as learning by doing, which is an important way to complete internalization process. The training internalization process is mainly done by internal employees. Since the superiors of the employees have a clear understanding of the work and situation of the positions, the on-the-job training requires the guidance of the higher-level supervisors.

\subsection{Teaching: Training Internal Teachers}

Teaching indicates that employees also need to share and pass on the experience they know and accumulate at work to other colleagues to promote knowledge sharing and avoid knowledge [22]. The process of teaching is the knowledge of the externalization and combination.

With the traditional enterprise employee training methods, enterprises generally rely on training instructors from external training institutions or colleges. However, the external training lecturers have shortcomings such as less practical experience and no understanding of the internal situation of the enterprise. It is an important part of the training new mode to train the internal training instructors through the internal teachers.

Employees can convert tacit knowledge such as knowledge learned in training and experience accumulated in the positions into explicit knowledge by writing course materials or job descriptions, which is convenient for sharing with other employees. As a lecturer or a master of the positions, the knowledge of the individual's implicitness is imparted to other employees by means of hands-on experience.

\section{Conclusions}

By discovering the intrinsic relationship between dynamic knowledge creation and enterprise training, this paper designs the enterprise training innovation model based on the four knowledge transformations of knowledge creation, and proposes a two-way circulation training mode of "learning-doing-teaching". This paper finds that the processes of socialization, externalization, combination and internalization are related to enterprise training. The dynamic knowledge creation process exists in the process of corporate training. The two interact and integrate each other to provide a new perspective for the positioning, process and strategy of the enterprise design training system, and supplement the research gap between the dynamic knowledge creation theory and the employee training rela- 
tionship. In order to promote the transformation of knowledge efficiently, this paper suggests that enterprises can establish internal face-to-face workshops or online learning network platforms, and develop targeted personal development plans for employees. In addition, enterprises can encourage employees to learn from current work or projects and form an internal trainer system.

This paper has some shortcomings in the design of enterprise training mode based on dynamic knowledge creation. This paper ignores the fact that knowledge creation is a spiral process from individual to organization, and focuses on the knowledge transformation process of individual employees. The SECI model emphasizes that the process of transforming from individual knowledge to organizational knowledge is dynamic and continuous. This paper finds that it is easy to realize the personal knowledge transfer of employees in the process of enterprise training, and it is necessary to transform from individual to organizational level. According to the above research findings and shortcomings, future research efforts can focus on the external role of enterprise training. This paper will further use the knowledge spiral process of person-organization to build the enterprise training model, explore the reasons that hinder knowledge transfer within and between organizations, and propose practical suggestions by case analysis.

\section{Conflicts of Interest}

The author declares no conflicts of interest regarding the publication of this paper.

\section{References}

[1] Alavi, M. and Leidner, D.E. (2001) Review: Knowledge Management and Knowledge Management Systems: Conceptual Foundations and Research Issues. MIS Quarterly, 25, 107-136. https://doi.org/10.2307/3250961

[2] Madhavan, R. and Grover, R. (1998) From Embedded Knowledge to Embodied knowledge: New Product Development as Knowledge Management. Journal of Marketing, 62, 1-12. https://doi.org/10.1177/002224299806200401

[3] Popadiuk, S. and Choo, C.W. (2006) Innovation and Knowledge Creation: How Are These Concepts Related? International Journal of Information Management, 26, 302-312.

[4] Ardichvili, A. (2008) Learning and Knowledge Sharing in Virtual Communities of Practice: Motivators, Barriers, and Enablers. Advances in Developing Human Resources, 10, 541-554. https://doi.org/10.1177/1523422308319536

[5] Davenport, T.P.L. (1998) Working Knowledge. Harvard Business School Press, Cambridge, MA.

[6] Ke, P. (2007) Knowledge Management. Science Press, Beijing, 62.

[7] Nonaka, I, Toyama, R. and Konno, N. (2000) SECI, Ba and Leadership: A Unified Model of Dynamic Knowledge Creation. Long Range Planning, 33, 5-34. https://doi.org/10.1016/S0024-6301(99)00115-6

[8] Yoshijiro, T.H. (2006) Enterprises that Create Knowledge: The Driving Force for Continuous Innovation of Japanese and American Companies. Intellectual Property 
Publishing House, Beijing, 192-205.

[9] Nonaka, I. and Konno, N. (1998) The Concept of 'Ba': Building Foundation for Knowledge Creation. California Management Review, 40, 40-54. https://doi.org/10.2307/41165942

[10] Lave, J. and Wenger, E. (1991) Situating Learning in Communities of Practice. Cambridge University Press, Cambridge. https://doi.org/10.1017/CBO9780511815355

[11] Koskinen, K. and Vanharanta, H. (2002) The Role of Tacit Knowledge in Innovation Processes of Small Technology Companies. International Journal of Production Economics, 80, 57-64. https://doi.org/10.1016/S0925-5273(02)00243-8

[12] Kari, J. (2009) Informational Uses of Spiritual Information: An Analysis of Messages Reportedly Transmitted by Extraphysical Means. Journal of Information Science, 35, 453-468. https://doi.org/10.1177/0165551508101860

[13] Nonaka, I. and Takeuchi, H. (1995) The Knowledge-Creating Company: How Japanese Companies Create the Dynamics of Innovation. Oxford University Press, Oxford.

[14] Boland, R.J. and Tenkasi, R.V. (1995) Perspective Making and Perspective Taking in Communities of Knowing. Organization Science, 6, 337-507. https://doi.org/10.1287/orsc.6.4.350

[15] Senge, P. (2002) The Fifth Discipline; The Art and Practice of The Learning Organization. Performance Improvement, 30, 37. https://doi.org/10.1002/pfi.4170300510

[16] Hippel, E, Thomke, S. and Sonnack, M. (1999) Creating Breakthroughs at 3M. Harvard Business Review, 77, 47-57.

[17] Gourlay, S. (2006) Conceptualizing Knowledge Creation: A Critique of Nonaka's Theory. Journal of Management Studies, 43, 1415-1436. https://doi.org/10.1111/j.1467-6486.2006.00637.x

[18] Tsoukas, H. and Mylonopoulos, N. (2003) Part Special Issue Introduction: Modelling Organizational Knowledge. Journal of the Operational Research Society, 54, 911-913. https://doi.org/10.1057/palgrave.jors.2601585

[19] Lopez-Nicolas, C. and Soto-Acosta, P. (2010) Adoption and Use Effects on Knowledge Creation: An Empirical Investigation in SMEs. International Journal of Information Management, 30, 521-528. https://doi.org/10.1016/j.ijinfomgt.2010.03.004

[20] Panahi, S, Watson, J. and Partridge, H. (2013) Towards Tacit Knowledge Sharing over Social Web Tools. Journal of Knowledge Management, 17, 379-397. https://doi.org/10.1108/JKM-11-2012-0364

[21] Siebdrat, F, Hoegl, M. and Ernst, H. (2009) How to Manage Virtual Teams. MIT Sloan Management, 50, 63-68.

[22] Zhang, W. and Watts, S. (2008) Online Communities as Communities of Practice: A Case Study. Journal of Knowledge Management, 12, 55-71. https://doi.org/10.1108/13673270810884255 